\title{
Adductor Group of the Leg
}

National Cancer Institute

\section{Source}

National Cancer Institute. Adductor Group of the Leg. NCI Thesaurus. Code C53039.

A group of muscles causing movement of the leg towards the midline of the body. 